\title{
Numerical analysis of spinal stabiliser in spondylolisthesis treatment with pedicle screws
}

\author{
Jarosław Zubrzycki ${ }^{1, *}$ \\ ${ }^{1}$ Lublin University of Technology, Mechanical Engineering Faculty, Nadbystrzycka 36, Lublin, Poland
}

\begin{abstract}
The aim of the research on experimental parts was to analyse the influence of the lumbar stabilisation on the strength aspects of the lumbar part of human spine and stabiliser in case of spondylolisthesis treatment. The models were built with the use of pre-surgical CT diagnostics, routinely used in medical practice. MIMICS software was used to process the results of the neuroimaging research and to create a 3D model. Two models were built: one with and the other without a stabilizer. Afterwards, a static load analysis for the load coming from the upper part of the body was done. Analysis was performed using the finite element method (FEA). The performed simulations enabled to determine the stress in particular discs for both models, with and without transpedicular stabiliser.
\end{abstract}

\section{Introduction}

Probably, there is none system in human body more important for human health and an active and long life than spinal. It provides a particular axis for the human body. Its specific structure protects the brain and the spinal cord from shocks and damages. The spinal system in a good condition enables to work nervous system properly and has got significant influence on healthy and full human life. It is built from hard bony structures (vertebrae) and elastic elements (intervertebral discs) being laid alternately. This system is stabilised and supported by soft tissues: joints, ligaments and muscles. Its structure facilitates moving and simultaneously transferring weight of a human body and load from daily activities [1].

A clinic practice shows that majority of a spinal problems occur in its lumbar part. This section is exposed to greater loads in comparison to a thoracic or a cervical section. Approximately $30 \%$ cases of orthopaedic conditions to patients are associated with the lumbar part. Almost all disruptions in stability derive from imbalance in muscles interaction, spinal disc degradation and degradation of intervertebral joints. It leads to deepening of a lumbar lordosis and has an influence on inappropriate adjustment in relation to a cross bone. These problems are mostly a consequence of exposure to mechanical loads. A ligament apparatus gets loose with age, which results in looseness within joints. What is more, a loss of muscles efficiency gradually contributes to instability in movement segments [2].

Typical overload break of spinal bone structures and one of many diseases of the lumbar section is spondylolisthesis. That disease is a form of chronic instability of the lumbar part of spinal. It consists in slipping from vertebrae column which are situated above a rest of them. Majority cases of spondylolisthesis in the lumbar section occur at a L5-S1 level, less commonly at L4-L5 and L3-L4 levels. The most frequently occurring ailments are associated with shaking and damage to nervous system or pathologic changes in a vertebra joint structure $[3,4]$.

\section{Spinal anatomy and physiology}

The spine is a moving axis of a body and a neck. The axis is situated in a midsagittal plane at a back part of the body. The spine begins at a skull base and ends at a bottom part of the body what together with ribs and a breastbone makes the skeletal system. The spinal cord is constructed of 33-34 odd and symmetrical built vertebra being laid one on another [5,6]. Depending on a spinal section it is divided into 5 parts (Fig. 1):

- Cervical (C1-C7) - 7 vertebrae,

- Thoracic (Th1-Th12) - 12 vertebrae,

- Lumbar (L1-L5) - 5 vertebrae,

- Sacral (S1-S5) - 5 vertebrae,

- Coccygeal (Co1-Co4/Co5) - 4-5 vertebrae.

Its strength and resistance are a result of a gradually stronger structure and bigger size of vertebrae. That type of construction provides good stiffness, endurance and elasticity at the same time. Due to that construction there is possibility to perform three basic functions: protection of the spinal cord, protection of a motion organ and being a body support [5-7]. 


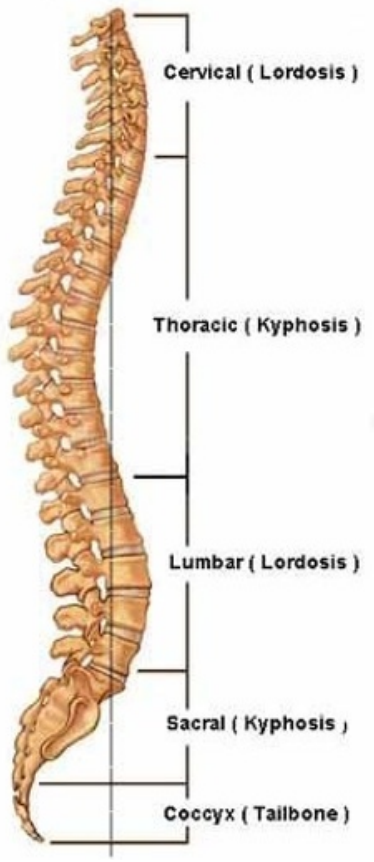

Fig. 1. Lateral (side) spinal column.

\subsection{The spinal curvature}

In the adult's sagittal plane are two types of the curvature: lordosis - curve knobs are turned into front side and kyphosis - curve knobs are turned into back side. Starting at the top in the spinal there are alternately occurring curves: cervical lordosis, thoracic kyphosis, lumbar lordosis and coccygeal kyphosis. Thanks to that construction, a double " $\mathrm{S}$ " shape is obtained. Mild transitions occur between cervical lordosis and thoracic kyphosis, thoracic kyphosis and lumbar lordosis. The transition between the last, fifth lumbar vertebra and sacral bone is greater and there is the possibility to stand out the lumbar-sacral angle. The last intervertebral vertebra curves to the front side as the elevation, however that name is accorded to the upper edge of the sacral bone [5-7].

The description of the spinal shape provided above is characteristic for humans, as it derives from the verticalisation of a body. The curves cause that the centre of gravity projection falls on the feet. When the centre of gravity projection falls beyond feet, a balance is lost. Differently, animals' centre of gravity projection falls before paws. That rule also concerns monkeys able to stand vertically for a while $[6,7]$.

\section{The spondylolisthesis}

The spondylolisthesis is a disease defined as a vertebral displacement (together with all vertebrae being above) in relation to vertebrae being below. Mostly, the spondylolisthesis occurs in the sections: L5-S1 and L4L5. The majority of authors says that the lumbar section is a mechanically weak point of human motion organ due to vertical position evolution, as a result the spondylolisthesis occurs in that spinal part mostly. The spondylolisthesis may occur in 5\% of general population. The name "spondylolisthesis" originates from Greek words "spondyl" - a spine and "olisthesis" - a slide. In 1782 it was the first time the spondylolisthesis had been described by the Belgian obstetrician Herbinaux who associated the unnatural spine protrusion into front side in relation to lumbar bone with problems during childbirth (the vertebra core protrusion L5 decreased permeability of the pelvic genital canal). From that moment, the spondylolisthesis became an object of examination for many orthopaedists, neurologists and biomechanics $[3,8,9,10,11]$.

\subsection{The term of spondylolisthesis degree}

For the rating of the advancement degree of the spondylolisthesis, used the Meyerding classification:

- 1st. level: the vertebra displacement in relation to each other less than to $25 \%$ of cord width,

- 2nd. level: the displacement to $50 \%$ of cord width

- 3rd. level: the displacement to $75 \%$ of cord width

- 4th. level: the greater or total displacement of cords in relation to each other [13].

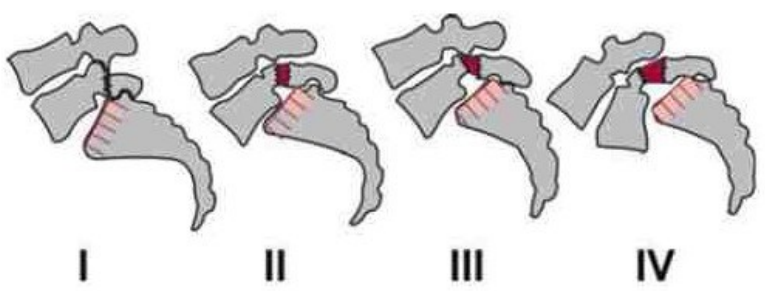

Fig. 2. The spondylolisthesis dividing [13].

In order to calculate a percentage of vertebra sliding, there is given formula:

$$
\mathrm{P}=\mathrm{A} / \mathrm{B} * 100 \%
$$

$\mathrm{P}$ - a percentage of a displacement;

A - a length of a cord section by a vertebra cord has moved in relation to a vertebra being laid above;

$\mathrm{B}$ - a weight of the whole cord;

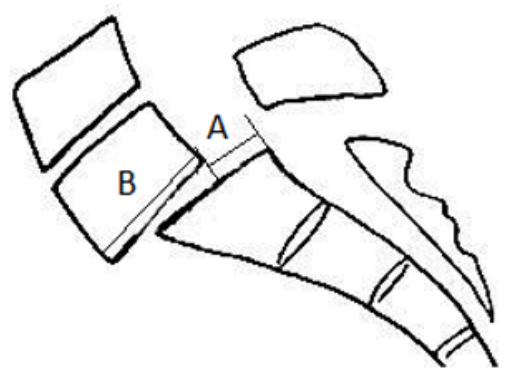

Fig. 3. Defining of the spondylolisthesis degree $[2,8]$.

\subsection{Treatment methods}

The spondylolisthesis treatment is based on behavioural and surgical management. The way of treating is decided by a doctor based on a patient observation, rating of radiographic examination and an advancement of a disease. The aim of treatment is to get a spinal stability and protect from neurobiological disorders[3,13-15] One of the general methods is setting special constructions of stabilisers - pedicle screws (fig. 4). 


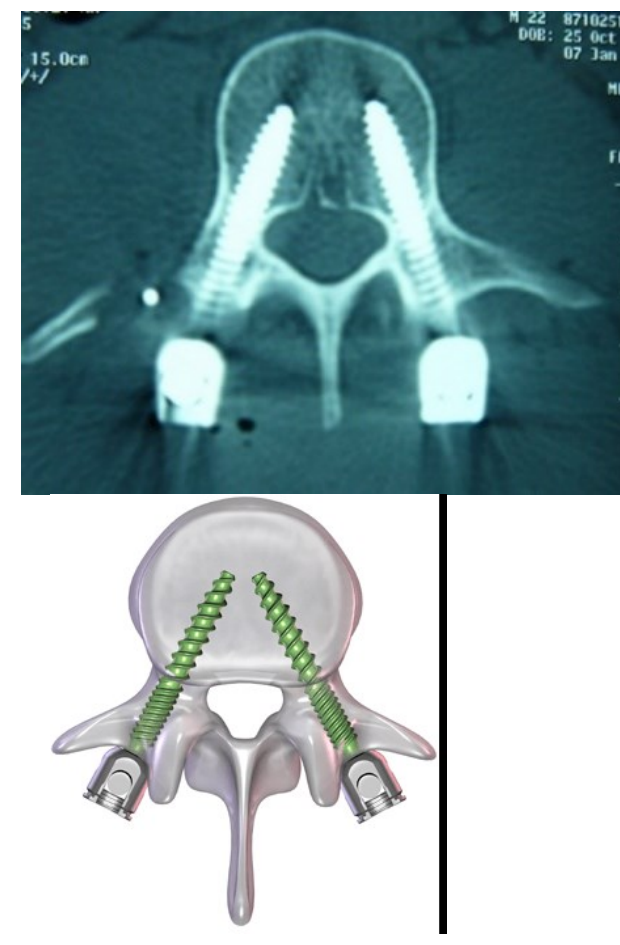

Fig. 4. Examples of pedicle screws usage [3].

\section{Numerical vertebra models}

Numerical models and numerical tests of endurance were done basing on $\mathrm{CT}$ results which were taken in cooperation with SPSK 1 in Lublin, the tests were totally anonymous. Vertebral geometry and their anatomical placement in relation to each other were created in Mimics and SolidEdge programs. The CT images were taken according to DICOM standard $[15,16]$. The data consists of 226 tomograms which were taken in resolution up to $1,25 \mathrm{~mm}$. The examined person is the woman 30 with the spondylolisthesis of the 2nd degree at the level L5-S1. Because of the spondylolisthesis placement for the further work there was taken only the spinal part i.e. L3, L4 and L5 vertebrae and sacral bone (fig. 5).

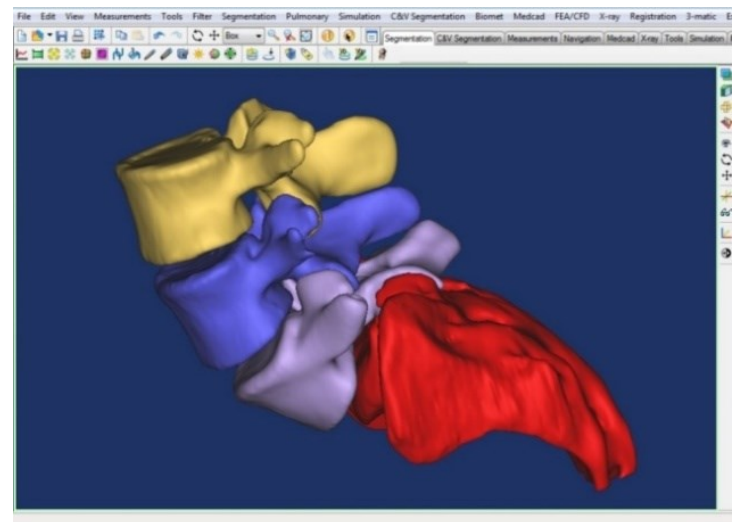

Fig. 5. The models of L3,L4,L5 vertebrae and sacral bone (Mimics).

\subsection{The simplification of numerical models}

That was obligatory for creating the simplified models because the CT images did not consist of the intervertebral discs structures $[13 ; 1]$. To give the shape and the relation between discs and vertebrae the simplification of given vertebral models was obligatory. The simplification assumes that alignment of the upper and the lower vertebral surface (removing of anatomical irregularity of these surfaces). Having managed with these activities, in the Assembly module there was done the resultative model of the examined spinal part (fig. 6) [1].

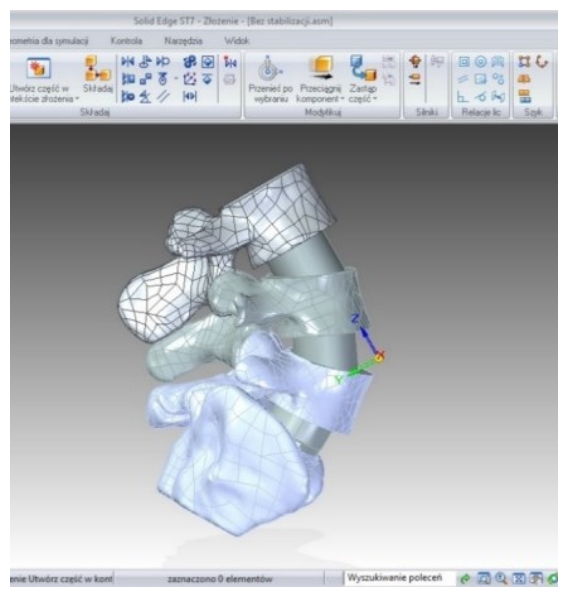

Fig. 6. Numerical spine model.

For such a designed model there were conducted numerical tests of the tension decomposition. The next stage of the work was designing the numerical model of the stabiliser being made by the pedicle screws. For this purpose, there was designed the attachment of the screws and the whole stabiliser construction. In the article, the simplified model of the stabiliser with the straight rods was presented. The curvatures were not taken into consideration which should be given to the rods, however due to the pre-examination of the curves there were left out. For the given assumptions the model of the spinal part is presented in fig. 7.

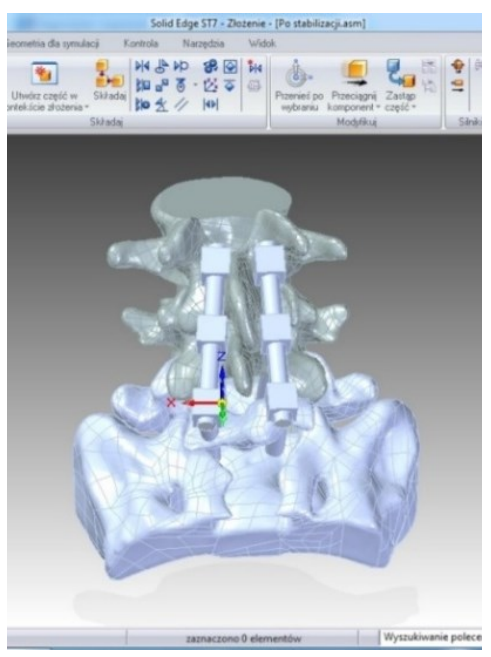

Fig. 7. Numerical spine model with stabilizer.

For the spinal stabilisation there were used the following elements: 6 pedicle screws and two connectors. The screws, made of titanium Ti-6Al-4V, are $8 \mathrm{~mm}$ in diameter and $55 \mathrm{~mm}$ in length. According to conducted examinations the $8 \mathrm{~mm}$ diameter screws can be safely used for L3 vertebra [9]. The connector is 6.5 
$\mathrm{mm}$ in diameter, $70 \mathrm{~mm}$ in length and it is made of titanium $6 \mathrm{Al}-4 \mathrm{~V}$. The screws were put into the vertebrae at the angle of $130^{\circ}$ in relation to $\mathrm{XZ}$ surface, at the angle of $5^{0}$ in relation to $\mathrm{YZ}$ axis at the left side, at the angle of $-5^{0}$ in relation to $\mathrm{YZ}$ at the right side.

\section{Numerical strength analysis}

The numerical examination of endurance was conducted by using Finite Elements Analysis (FEA). The analysis was conducted for two cases:

1. For anatomical spinal with the diagnosed spondylolisthesis,

2. For the spinal "after the surgery" with the implemented transpedicular stabiliser.

\subsection{Input data for the analysis}

Strength analysis was conducted for the load coming from the upper body part with $500[\mathrm{~N}]$ force, which was applied, to the upper part of L3 vertebra cord, what enabled to define the tension state in the particular vertebrae. The model fixation was applied to the sacral bone. The vertebral and the intervertebral discs material was adopted as the isotropic. The features of the vertebrae and the discs were appointed after the research analysis and publication. The features were shown in the table below $[13,2,4]$.

Tab. 1. The material features for FEM analysis [20].

\begin{tabular}{|c|c|c|}
\hline Material & $\begin{array}{c}\text { Young } \\
\text { module } \\
{[\mathrm{MPa}]}\end{array}$ & Poisson number \\
\hline Vertebra & 10000 & 0.3 \\
\hline Intervertebral disc & 100 & 0.4 \\
\hline $\begin{array}{c}\text { Screws and connectors } \\
\text { (Titanium Ti 6Al 4V) }\end{array}$ & 104800 & 0.31 \\
\hline
\end{tabular}

\subsection{FEM analysis}

Firstly, there was conducted physiologic analysis of the lumbar section. There were used input data which, the same as in Tab. 1. Received results of tensions decomposition were shown in the following images. FEM analysis was conducted by Huber - von Mises hypothesis [21]. In Fig. 8 are given discretisation of finite element mesh model.

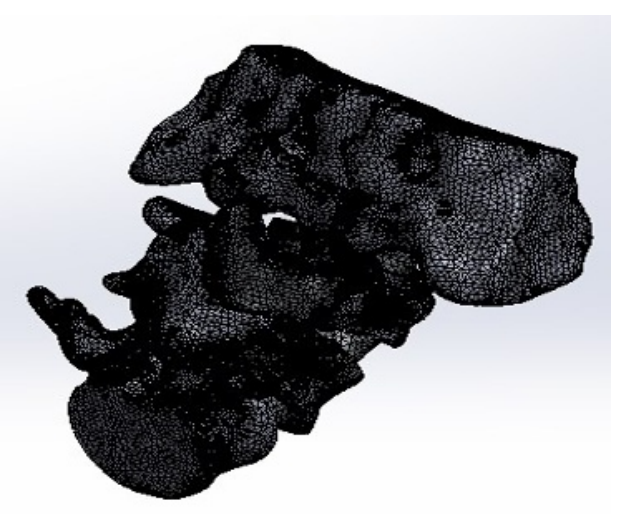

Fig. 8. Discretisation of finite element mesh model.

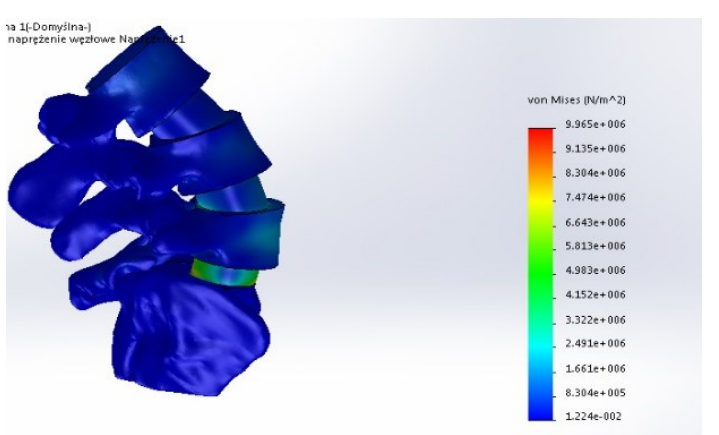

Fig. 9. Stress pattern in the model without stabiliser - general view.

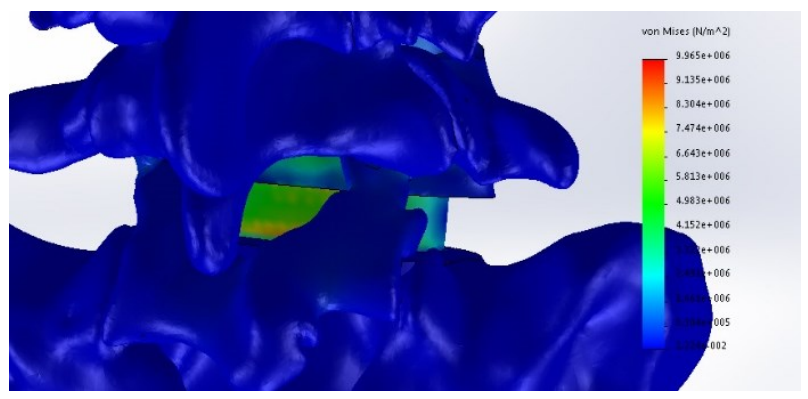

Fig. 10. Stress pattern in the model without stabiliser - details.

In the given figures above, it is easy to see the tensions concentration in the back and front side of intervertebral disc between L5 vertebra and the sacral bone $(7,13 \mathrm{MPa})$. In the same vertebrae, tensions do not reach too high value and are evenly decomposed overall its surface. The observed tensions concentrations are very dangerous for a patient due to a possible significant disc's damage, which can result in a discopathy, or further in spondylolisthesis, and growth in vertebral cord pressure. In the limiting case there may occur a loss of sensation in lower limbs and loss of moving ability [22].

Total displacements of the model under load, shown in Fig. 11, are very interesting.

In the further sequence the spinal lumbar section model with the transpedicular stabiliser was taken into the analysis. The analysis of the received maps of tensions decomposition in the tested element showed that the used supporting construction in the form of mentioned above stabiliser allowed to decrease tensions affecting the vertebrae and the intervertebral discs (fig. $12,13)$.

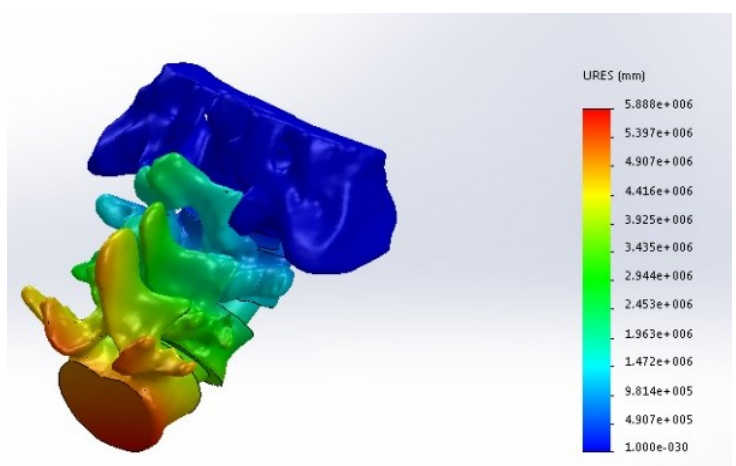

Fig. 11. Total displacements of the model under load. 
Inserting the stabiliser to the lumbar region of the examined person caused that almost all of tension was transferred to the stabiliser rods (fig. 12a). Thanks to this, the deformed spine section was unloaded, and these sections can be subjected to corrective operations and rehabilitation (fig. 12b). Basing on the results, the greatest reduced tensions by Huber - von Mises hypothesis were encountered in the stabiliser rods and the maximal value $390 \mathrm{MPa}$ was reached. It means that there was a rise of tensions value in the system with the stabiliser in relation to the physiological model what particularly results from spinal biomechanics changes and the significantly bigger cross-section of the spinal vertebrae and the intervertebral discs in comparison to the cross-section of stabiliser rods $(d=6,5 \mathrm{~mm} ; \mathrm{l}=70 \mathrm{~mm})$ and the screws $(\mathrm{D}=8 \mathrm{~mm})$.

a)

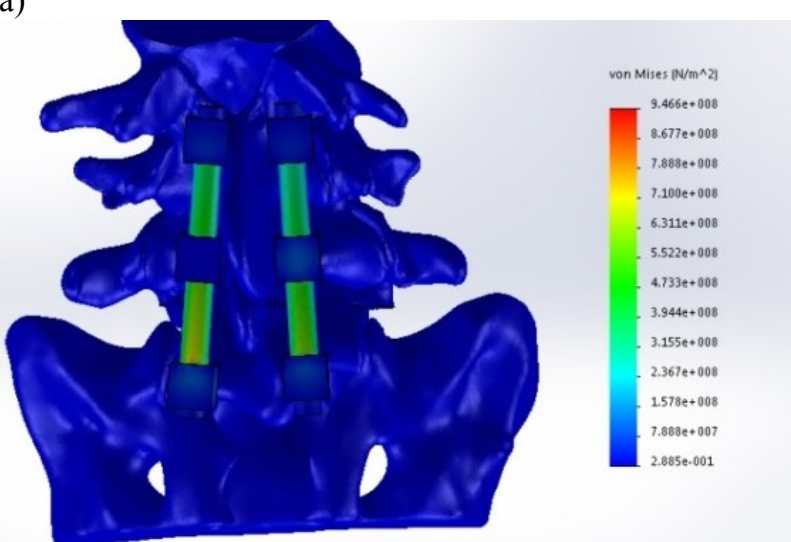

b)

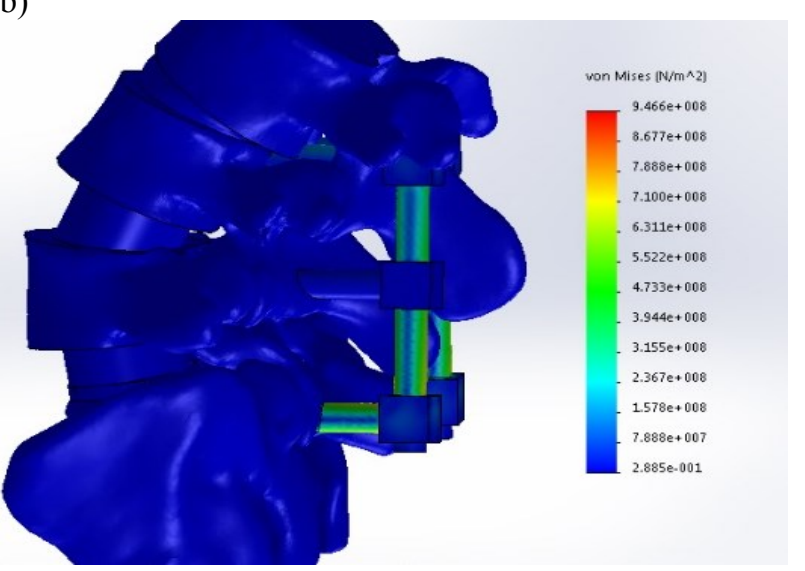

Fig. 12. Stress pattern in the model with stabiliser: a) coronal plane, b) sagittal plane.

What was significant, great values of tensions in the stabiliser screws were observed. It concerned the fixed screws in the L4 vertebra and the sacral bone (fig. 12). Whereas tensions on the screws placed in the L5 vertebra were minor in relation to the screws which are mentioned above.

Based on the obtained simulation information, it can be concluded that the implementation of this solution in the form of a transpedicular stabiliser can significantly diminish the damaged area of the spine and improve the quality of patients' life.

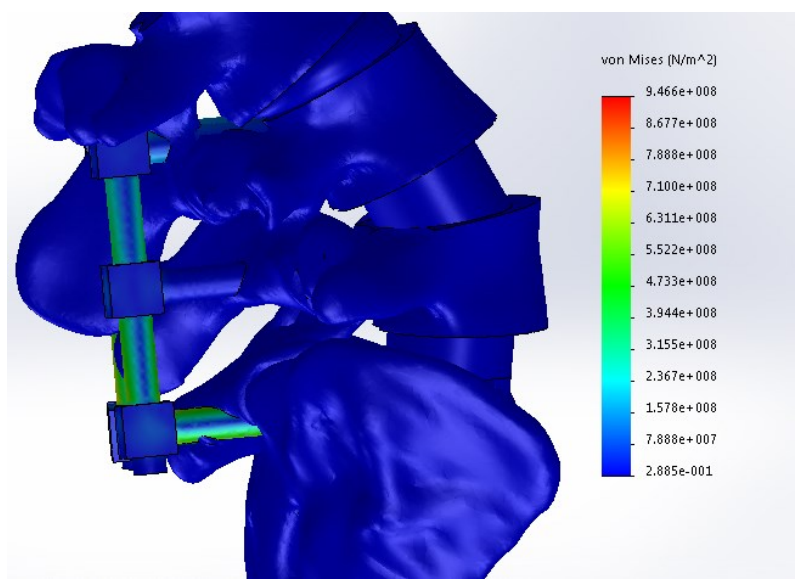

Fig. 13. Stress pattern in the model with stabiliser - details.

\section{Conclusions}

The paper describes the complex mechanical system which is a stabilising spinal segment in case of the 2nd degree L5$\mathrm{S} 1$ spondylolisthesis occurring in the women $30 \mathrm{~s}$. The rate of the transpedicular stabilisation influence on the biomechanics of the human lumbar section of the spine was conducted by using the two different spinal models: physiological and with the transpedicular stabiliser. Models were made by using CT images. The MIMICS software was used for the tests results processing. Then the models were imported to the CAD software. Then, models of vertebrae and intervertebral discs without the stabiliser and with the transpedicular stabiliser were created. On the built models there was conducted static analysis for the tension coming from the upper body part.

Based on the analysis of the results obtained from the simulation of the static load of the physiological model, it was found that in this spondylolisthesis type, the mostloaded areas are: the posterior and anterior part of the intervertebral disc located between the L5 vertebra and the sacral bone. Transpedicular screws are used to stabilise and unload these structures. The second analysis was conducted on the model with the transpedicular stabilisation and that analysis proved that installation of the transpedicular stabilisation in the spine leads to stiffening and stabilisation of the system. The intervertebral disc and L5 vertebra were loaded and tensions were transferred by screw connectors and screws fixed to L4 vertebra and to the sacral bone.

In the contemporary engineering the finite element method is widely used. That method was used for better recognition of a disease entity in the spinal lumbar section (spondylolisthesis) and rating its treatment by using transpedicular stabilisation system. The usage of that method allowed: closer recognition of the anatomy, the physiology and kinematic of the spine affected with the L5-S1 spondylolisthesis type II, as well as rating of effectiveness of its treatment with transpedicular screws.

Despite the fact that there were some simplifications of the FEM reality mapping, it can be widely used for medical aims. It allows constructing prosthesis dedicated for a given patient and brings closer biomechanics systems in specific disease entities. It significantly advances the design process and eventually reduces the value of offering products, making them more accessible to the public. 


\section{References}

1. J. Zubrzycki, N. Smidova, Applied Mechanics and Materials. 613, 172-181 (2014)

2. S. Thakar, L. Sivaraju, S. Aryan, D. Mohan, N. A. Sai Kiran, A. S. Hegde, Journal of Neurosurgery: Spine. 24, 679-685 (2016)

3. J. Kiwerski, Schorzenia $i$ urazy kręostupa (Wydawnictwo Lekarskie PZWL, Warszawa, 2003)

4. M. Gzik, M. Joszko, J. Pieniążek, Modelowanie Inżynierskie, 109-116 (2012)

5. P. Pétursson, K. J. Edmunds, M. K. Gíslason, B. Magnússon, G. Magnúsdóttir, G. Halldórsson, H. Jónsson, P. Gargiulo, Computational and Mathematical Methods in Medicine. 2015, 1-7 (2015)

6. D. Hoy, L. March, P. Brooks, F. Blyth, A. Woolf, C. Bain, G. Williams, E. Smith, T. Vos, J. Barendregt, C. Murray, R. Burstein, R. Buchbinder, Annals of the Rheumatic Diseases. 73, 968-974 (2014)

7. W. Woźniak, R. Aleksandrowicz, Edra Urban \& Partner, Anatomia człowieka: podręcznik dla studentów $i$ lekarzy (Edra Urban \& Partner, Wrocław, 2017)

8. M. Reicher, T. Bilikiewicz, S. Hiller, E. Stołyhwo, E. Sieńkowski, W. Łasiński, Wydawnictwo Lekarskie PZWL, Anatomia ogólna: kości, stawy $i$ więzadła, mięśnie (Wydawnictwo Lekarskie PZWL, Warszawa, 2013)

9. O. Narkiewicz, J. Dziewiątkowski, J. Moryś, S. Scisłowska, W. Kubik, Wydawnictwo Lekarskie PZWL, Anatomia człowieka: podręcznik dla studentów. T. 2, T. 2, (Wydawnictwo Lekarskie PZWL, Warszawa, 2015)

10. R. Będziński, Biomechanika inżynierska: zagadnienia wybrane (Oficyna Wydawnicza Politechniki Wrocławskiej, 1997)

11. A. Ganju, Neurosurgical Focus. 13, 1-6 (2002)

12. V. Sasidhar, thesis, University of Toledo (2004)

13. Y. Jiang, X. Peng, Y. Wang, C. Fu, X. Sun, K. Zhang, British Journal of Applied Science \& Technology. 6, 508-519 (2015)

14. U. Chamoli, A. D. Diwan, N. Tsafnat, Journal of Biomedical Materials Research Part A. 102, 33243340 (2014)

15. H. Bozkus, C. A. Dickman, Journal of Neurosurgery: Spine. 100, 62-65 (2004)

16. K. Torres, G. Staśkiewicz, M. Śnieżyński, A. Drop, R. Maciejewski, Folia Morphologica. 70, 1-4 (2011)

17. M. Frame, J. S. Huntley, The Scientific World Journal. 2012, 1-7 (2012)

18. J. Zubrzycki, M. Braniewska, Mechanik, 46-47 (2017)

19. I. Zafarparandah, D. U. Erbulut, I. Lazoglu, A. F. Ozer, Turkish Neurosurgery (2013), doi:10.5137/1019-5149.JTN.8486-13.0

20. R. Karpiński, Ł. Jaworski, J. Zubrzycki, ITM Web of Conferences. 15, 07015 (2017)

21. J. Zubrzycki, R. Karpinski, L. Jaworski, A. M. Ausiyevich, N. Smidova, Science \& Technique. 17, 165-172 (2018)

22. R. Karpiński, Ł. Jaworski, J. Zubrzycki, Advances in Science and Technology Research Journal. 10, 240-246 (2016) 